\title{
Taming of Whip-Lash Effect in Forecasting for Automotive Spare Parts Industry using Minitab and Excel Spread Sheet
}

\author{
A. Naga Phaneendra \\ Dept. of Mechanical \\ Engineering \\ S.V.U College of Engineering \\ Tirupati
}

\author{
V. Diwakar Reddy \\ Professor \\ Dept. of Mechanical \\ Engineering, S.V.U College of \\ Engineering, Tirupati
}

\author{
G. Krishnaiah \\ Retd. Professor \\ Dept. of Mechanical \\ Engineering, S.V.U College of \\ Engineering, Tirupati
}

\begin{abstract}
This paper investigates the proliferation and exaggeration of order variances (i.e., Whip-Lash Effect) in supply chain. The supply chain engages manufacturer, distributor and retailer for goods transactions with (or) without sharing reliable information which leads to backorders (or) over orders. The paper analyses the orders placed by a distributor to manufacturer in a stationary demand scenario. The previous demand data of twenty four months is collected from the automotive spare parts industry and forecasted for the next two years using Triple exponential smoothing model namely Holts winters model. The smoothing parameters that influence the forecast data are analyzed. Finally the optimum smoothing parameter that minimizes the Whip-Lash Effect is predicted in Minitab software by considering various levels of alpha, beta and gamma values and the results are tabulated in excel spread sheets.
\end{abstract}

\section{Keywords}

Supply chain Management, Whip-Lash Effect, Minitab,

\section{INTRODUCTION}

Bull-whip effect (or) whip-lash effect initially conceived by Procter and Gamble [15] but disseminated by [7], for the aspect where the variance of the demand signal increases in response to demand signal that flows up the supply chain. It has been an enigma concern for a long time as initiated by [3] and [8]. Certainly, there is no lack of empirical evidence from industry. For example, [6] documents a confectionary supply chain where the bullwhip increases the variance of the orders by 9 to 1 in a high volume product and 28 to 1 in a slow moving product. [1] present empirical evidence and theoretical results based on the $(\mathrm{s}, \mathrm{S})$ model and highlight the link between bullwhip and inventory variance for auto regressive (AR) demand.

A pervasive research has been supervised to examine the effect of order variance in supply chains. The instances in which the fluctuations in the order placement increases from customers to manufacturers. Perceptions from industry operations [9] Macro Economics data (Holts) and simulated experiments explore enormous total supply chain costs due to whip lash effect issue [2]. The extensive research is prevailing to mitigate the effect through statistical approach. The operational causes that leads to order variance are predicted through managerial insights and measures adapted to quantify the factors [7].

A system of control framework was introduced to study the whip-lash effect. [11], [12], [13], [14] developed relations for the variance of the orders streams at any point in the network based on operating policies. The model predicts whether or not the whip-lash effect will arise. When consumer demand is typical to determine or mitigate vigorous indicative tests (i.e., the tests that holds the customer demand independently) are focused for the existence of the whip-lash effect at any segment of the supply chain [16].

Earlier studies focus on taming whip-lash effect through empirical based relations with combination of policies. A very few studies have proved the robustness of the meta-heuristic approach for predicting the smoothing parameters to alleviate the order variance. We have selected winters (Triple Exponential smoothing) model to forecast the data in Minitab and furthermore, various levels of smoothing constants are swapped to draw optimum results that tends to least order variance.

\section{PROBLEM DESCRIPTION AND FORMULATION}

In this paper a supply chain comprised of one manufacturer, Distributor, and Retailer are considered. In the chain a multiple inventory flows from manufacturer to retailer. At each stage of supply chain the demand varies indefinitely due to seasonal impact. Due to uncertainty in demand the manufacturer produces the multiple inventories in large quantity regardless of its succeeding chain demand. As a result the accumulation of inventory pileup enormously which leads to increase in total cost of inventory. Earlier researches focused on minimizing total cost by formulating mathematical equations and simplifying in optimization tools to achieve best optimum number of inventories and orders. This paper aims to minimize the order variance by considering the various levels of smoothing parameters and swapping them in combination to draw necessary outputs that alleviate demand uncertainty at each levels of supply chain.

\subsection{Holts-Winters Model}

The Holts-Winters model is appropriate when the systematic component of demand has a level, a trend and a seasonal factor. In this case we have

$\mathrm{F}(\mathrm{t}+1)=(\mathrm{Lt}+\mathrm{Tt}) * \mathrm{St}+1$--- Forecast for the succeeding period.

On observing demand for period $t+1$, we revise the estimates for Level, trend and seasonality factors as follows:

$\mathrm{L}(\mathrm{t}+1)=\alpha^{*}(\mathrm{D}(\mathrm{t}+1) / \mathrm{S}(\mathrm{t}+1))+(1-\alpha) *(\mathrm{Lt}+\mathrm{Tt})$ Level

$\mathrm{T}(\mathrm{t}+1)=\beta^{*}(\mathrm{~L}(\mathrm{t}+1)-\mathrm{Lt})+(1-\beta) \mathrm{Tt}$

-----------Trend 
$\mathrm{S}(\mathrm{t}+\mathrm{p}+1)=\Gamma^{*}(\mathrm{D}(\mathrm{t}+1) / \mathrm{L}(\mathrm{t}+1))+(1-\Gamma) \mathrm{S}(\mathrm{t}+1)$

\section{Seasonality}

\subsection{DESIGN OF EXPERIMENT}

The purpose of the design of experiment is to analyze the impact of

a) Smoothening parameters $(\alpha, \beta, \gamma)$,

b) Trend component

c) Strength of seasonality

On the quantification of bullwhip effect and on relation between whip-Lash effect and smoothing parameters

\subsubsection{Dependent variable}

The dependent variable is Bullwhip ratio. It is the ratio of quantity ordered by the retailer to the manufacturer to order (or) demand observed by the retailer.

\begin{tabular}{|c|c|c|}
\hline \multicolumn{3}{|c|}{ 2.2.2 Smoothening parameters } \\
\hline Alpha (0.05 to 0.30) & Beta ( 0.05 to 0.30$)$ & Gamma ( 0.05 to 0.30$)$ \\
\hline \multicolumn{3}{|c|}{ 2.2.3 Strength of Seasonality } \\
\hline Low seasonality & Medium seasonality & High seasonality \\
\hline
\end{tabular}

\subsection{Whip-Lash Effect}

The amplification in upstream of the supply chain is measured through demand variance. (Lee et al.(1997b)) suggested the modifications of the demand variance in upstream as the measure of the Whip-Lash Effect. It is certainly a good measure only when the units of flow are not changing along the chain. The demand perturbations in supply chain at various stages are shown in Figure 1.The relation is shown below:

Whip-Lash Effect Ratio $=\frac{\boldsymbol{\sigma}^{2} \text { order }}{\boldsymbol{\sigma}^{2} \text { Demand }}$
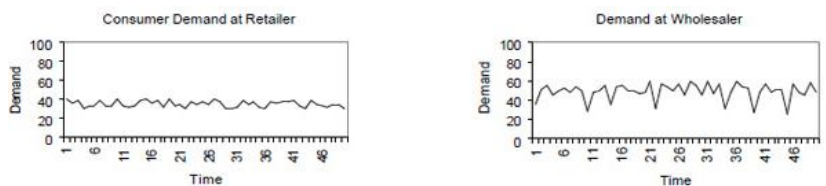

Demand at Manufacturer
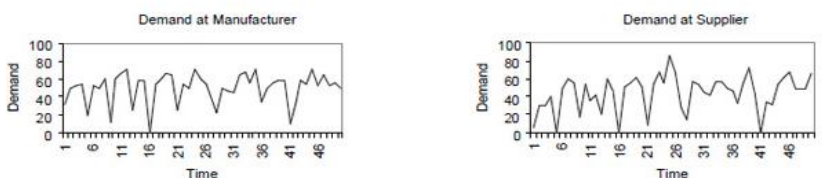

Fig 1: Demand Perturbations at distinct levels within the Supply chain

\subsection{Assumptions}

1) Multiple spare-parts are considered as a single Inventory.

2) Twenty four months of data is collected for forecast

3) Three levels of smoothing parameters are considered for Swapping as shown in Table 1.

4) Demand is stationery and uniform in all periods

5) No back order is allowed

\section{STEPS INVOLVED FOR COMPUTATION}

1) Divide the smoothing parameters into three levels

2) Selection of wide range of $\alpha, \beta$ and $\Gamma$ values as shown in Table 1

3) Incorporating first level of $\alpha, \beta$ and $\Gamma$ to Holtswinters Model for forecasting

4) Computing Whip-Lash effect ratio for all levels of Swapped smoothing parameters.

5) Representation of whip-lash effect ratios of Corresponding smoothing values on graph

6) Predicting optimal smoothing parameters in graph over Supervision.

The real time data of automotive spare parts at various stages are collected and are shown in Table 2.The amount of inventory possessed by the Manufacturer, Distributor and Retailer and varied invariably. Inventory from first level to last stage is decreased gradually and the Whip-Lash effect abnormally increased from retailer to manufacturer. The resent work focuses on the order variance and made minute effort to mitigate the effect to less impact.

Table 1: Optimal Parameters of three level supply chain

\begin{tabular}{|c|c|c|c|}
\hline \multicolumn{4}{|c|}{ Whip-Lash Effect Ratio is Minimum at this range } \\
\hline \multirow{2}{*}{ Supply chain stages } & \multicolumn{3}{|c|}{ Smoothing Parameters } \\
\hline & Alpha ( $\alpha)$ & Beta $(\beta)$ & Gamma $(\Gamma)$ \\
\hline Manufacturer & $0.05-0.30$ & $0.05-0.30$ & Less than 0.30 \\
\hline Distributor & $0.05-0.30$ & $0.05-0.30$ & Less than 0.30 \\
\hline Retailer & $0.05-0.30$ & $0.05-0.30$ & Less than 0.30 \\
\hline
\end{tabular}


Table 2: Historical Demand Data of three level supply chains

\begin{tabular}{|c|c|c|c|}
\hline MONTH & $\begin{array}{c}\text { MANUFACTURER } \\
\text { DEMAND }\end{array}$ & $\begin{array}{c}\text { DISTRIBUTOR } \\
\text { DEMAND }\end{array}$ & $\begin{array}{c}\text { RETAILER } \\
\text { DEMAND }\end{array}$ \\
\hline Jan'2015 & 5320 & 3125 & 2987 \\
\hline Feb'2015 & 2458 & 3548 & 2254 \\
\hline March'2015 & 3214 & 2548 & 1967 \\
\hline April'2015 & 2771 & 1987 & 1789 \\
\hline May'2015 & 7054 & 5487 & 4873 \\
\hline June'2015 & 6879 & 4898 & 3015 \\
\hline July'2015 & 8461 & 5874 & 3594 \\
\hline Aug'2015 & 10902 & 7987 & 6874 \\
\hline Sep'2015 & 20546 & 17846 & 14871 \\
\hline Oct'2015 & 20874 & 15694 & 11201 \\
\hline Nov'2015 & 22516 & 18654 & 10589 \\
\hline Dec'2015 & 8506 & 9574 & 6874 \\
\hline Jan'2016 & 7251 & 6874 & 4589 \\
\hline Feb'2016 & 1895 & 1587 & 1345 \\
\hline March'2016 & 5324 & 4785 & 3987 \\
\hline April'2016 & 3587 & 2865 & 1937 \\
\hline May'2016 & 5416 & 4987 & 2597 \\
\hline June'2016 & 4698 & 3456 & 4687 \\
\hline July'2016 & 6487 & 4897 & 6874 \\
\hline Aug'2016 & 12541 & 10205 & 8794 \\
\hline Sep'2016 & 19560 & 16895 & 13587 \\
\hline Oct'2016 & 21654 & 19871 & 15784 \\
\hline Nov'2016 & 24600 & 23548 & 19784 \\
\hline Dec'2016 & 7856 & 5481 & 3547 \\
\hline
\end{tabular}

The data is incorporated in Minitab and Holts-winters model in time series is selected by substituting respective smoothing parameters in dialogueboxas shown in Fig 2 and Fig 3 


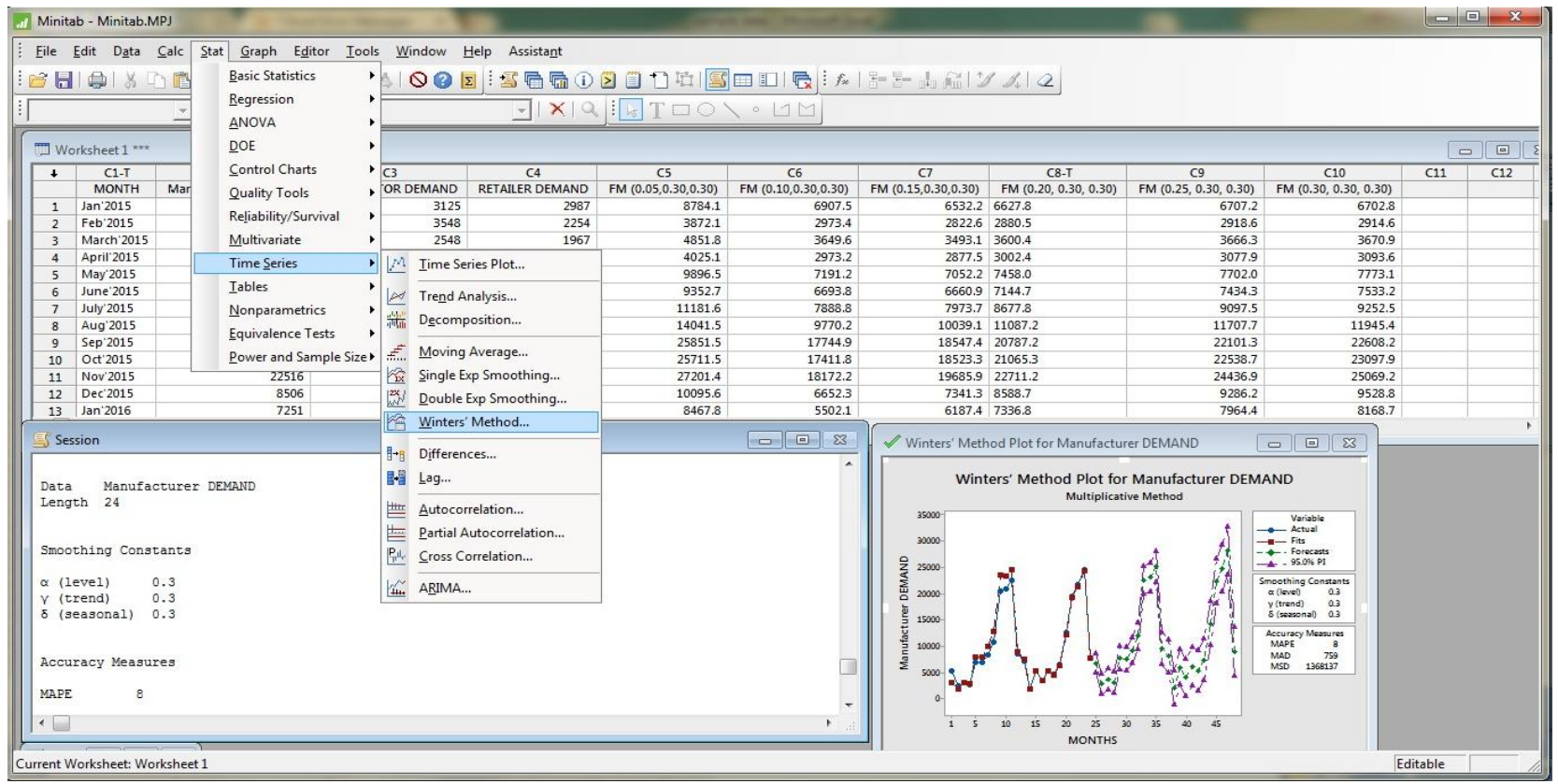

Fig 2: Forecast computation for Manufacturer

The Computations of Forecast and necessary relative graphs for the next periods are generated automatically and are shown in Figure 3. The forecast for the retailer is estimated keeping $\beta, \Gamma$ values constant and varying $\alpha$ values as shown in Figure 4.

The smoothing parameters are divided into three levels and computations have been done keeping one parameter as constant and varying other two parameters. Firstly, value of $\alpha$ is taken as 0.05 and $\beta, \Gamma$ are taken as 0.30 as a constant value for Manufacturer. Secondly, value of $\beta$ is considered as varying parameter and $\alpha, \Gamma$ as constant parameters. Similarly, the computations are performed for Distributor and retailer and the tables are not shown in this paper.

$\triangle$ Minitab - Minitab-D1.MPJ

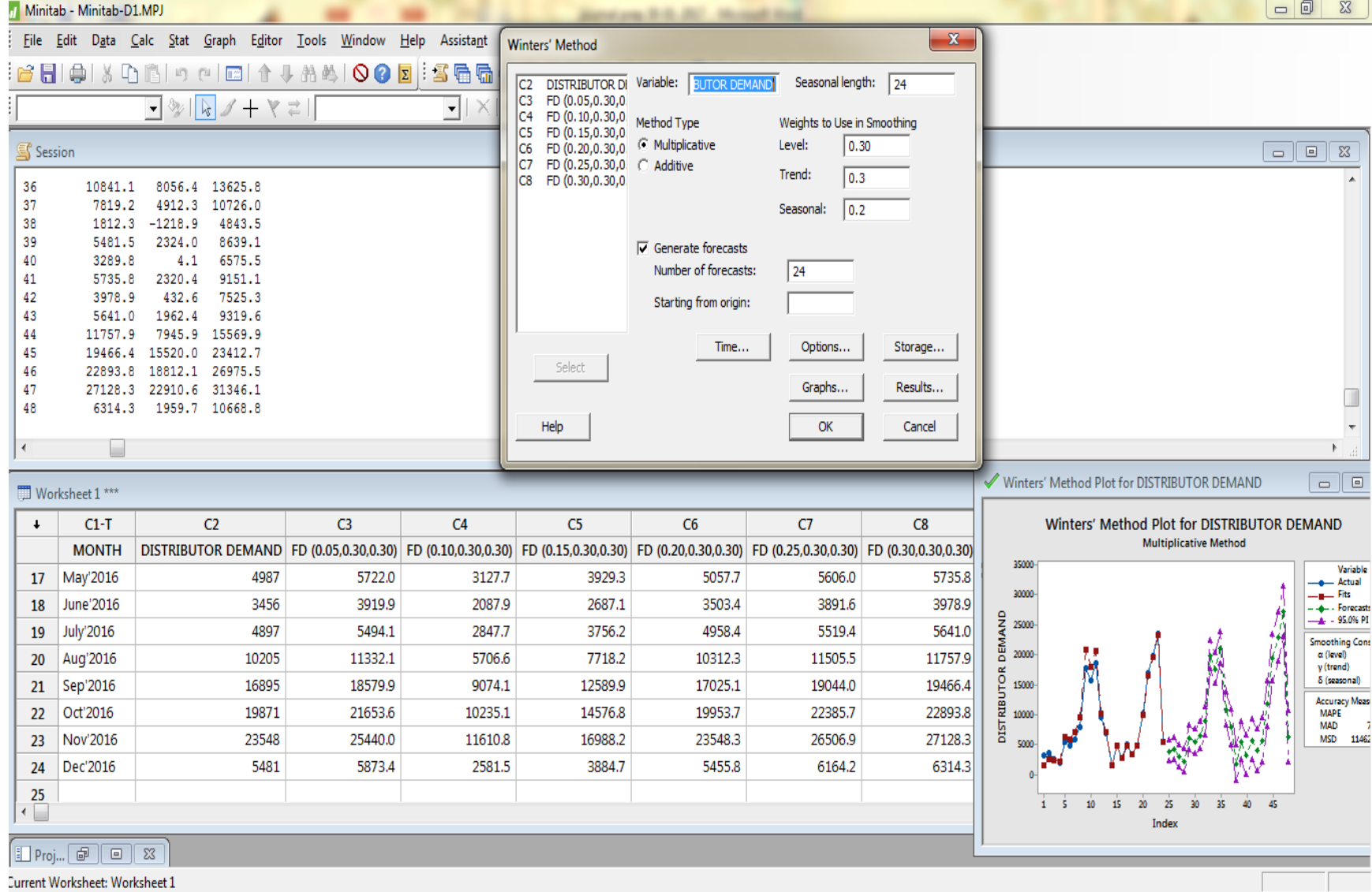




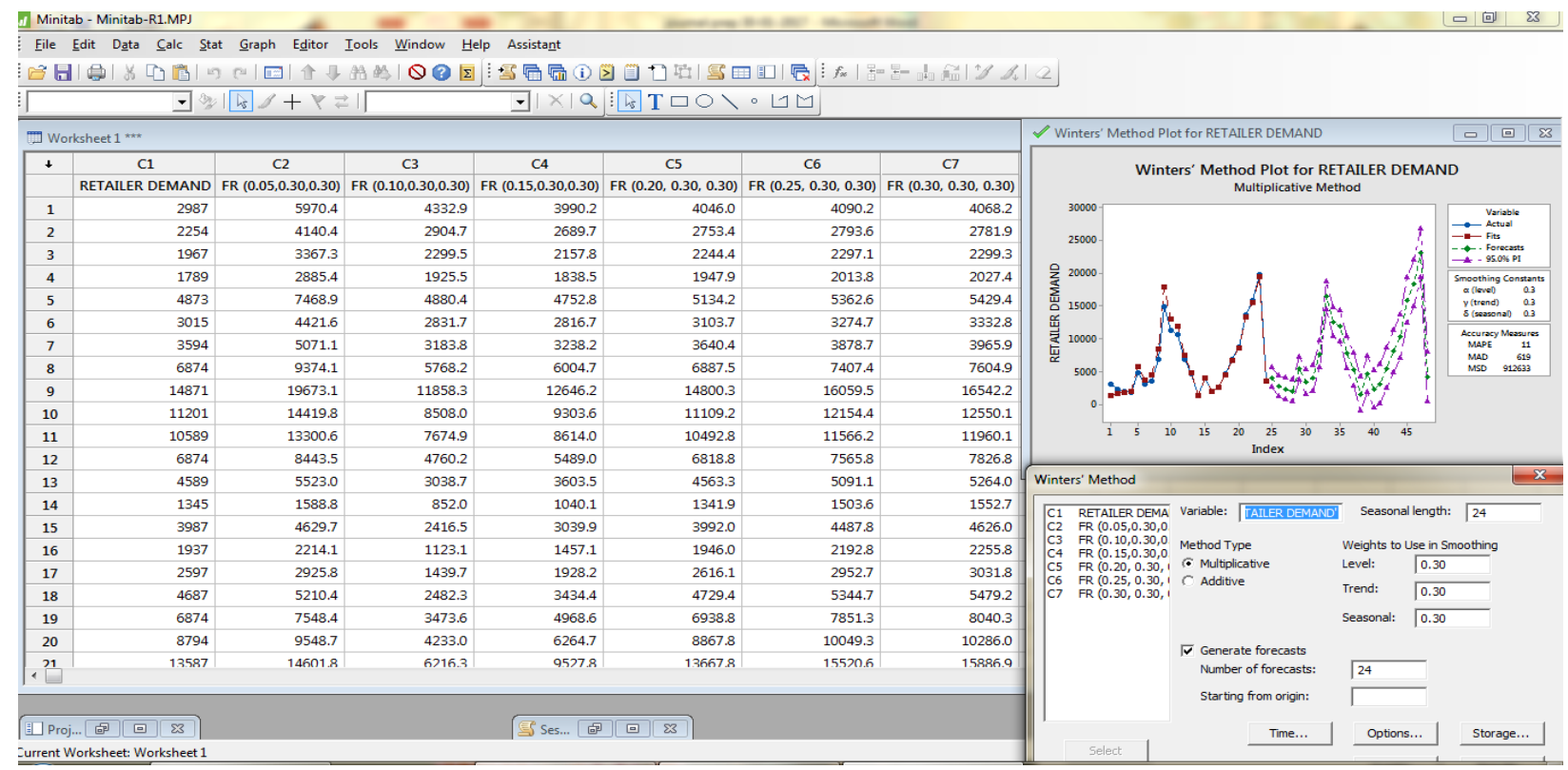

Fig 4: Forecast computation for Retailer

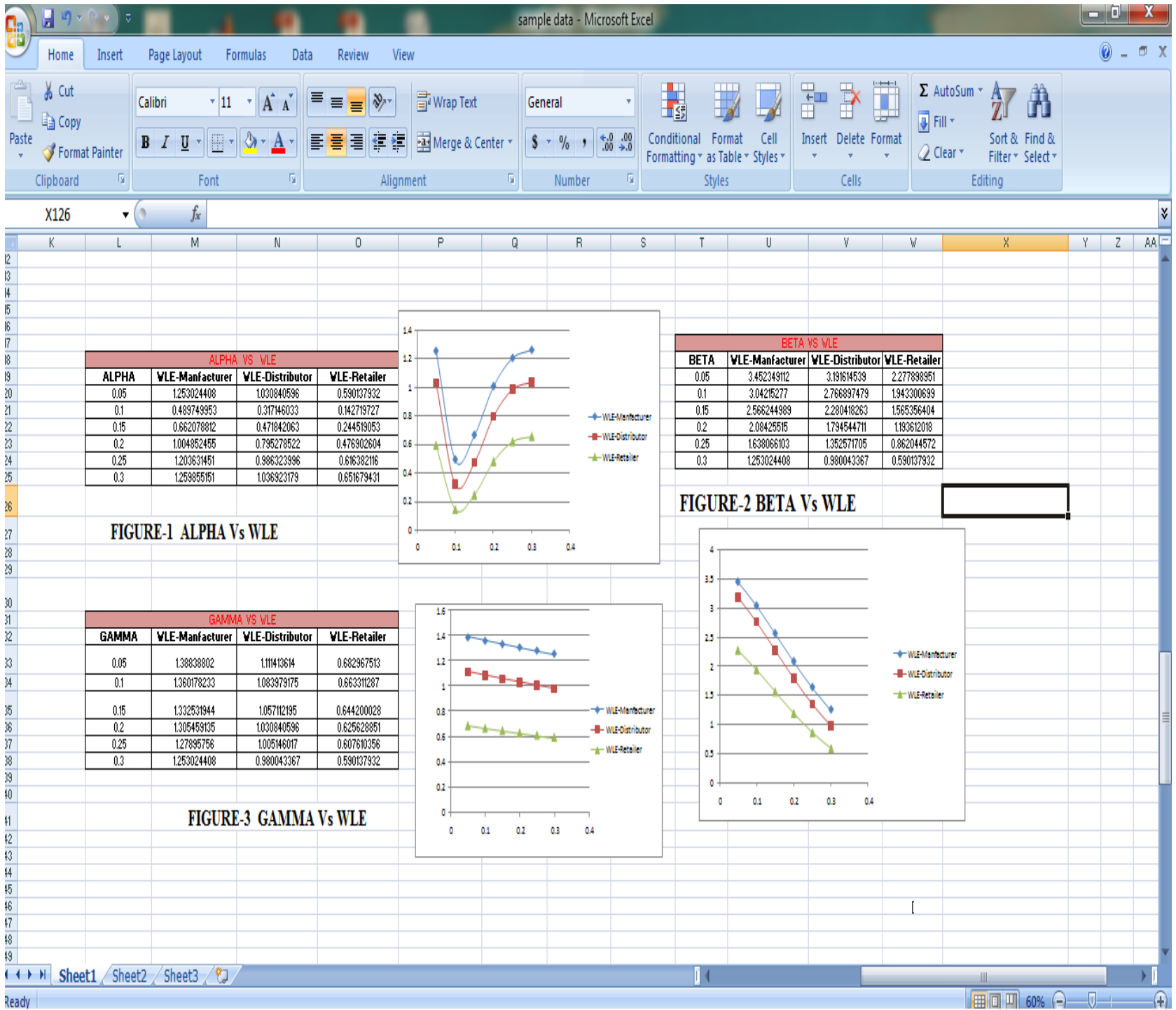

Fig 5: Representation of Whip-Lash Effect With respect to Alpha, Beta and Gamma values 


\section{RESULTS AND CONCLUSIONS}

The Research paper primarily focused on mitigation of order amplification, interchanging the smoothing parameters using Minitab software and Excel spread sheets. The results shown in Figure 5, elucidates the optimum values of $\alpha, \beta$ and $\Gamma$ values for Manufacturer, Distributor and Retailer. The Graph Alpha vs. Whip-Lash Effect is drawn for three supply stages and the result shows that the optimum values lies approximately nearer to $\alpha=0.10$ for all the three supply stages and the remaining values of Alpha value leads to drastic increase in order variance. From the experimental results it is suggested that, for the lower values of Alpha, the order amplification can be kept as low as possible. Similarly, The Whip-Lash Effect for all the three supply stages is Minimum for the Lower values of Beta and Gamma (i.e., 0.30 ) that can be shown in Figure 5. Furthermore, large quantity of demand data renders accurate forecast and the discrepancies among demand can be predicted with respect to level, trend and seasonal factors.

\section{FUTURE SCOPE}

1) The demand data is used to train and forecast for the Specified period in ANN (Artificial Neural Network)

2) Heuristic search techniques and optimization algorithms is Used to predict best combination of smoothing Parameters That minimizes the WhipLash Effect.

\section{ACKNOWLEDGMENTS}

The authors would like to thank the automotive Industry for sharing their valuable information to carry-out the research. The statements made herein are solely the responsibility of the authors. The authors are also grateful to anonymous reviewers that led to improvements in the paper.

\section{REFERENCES}

[1] Baganha, M.P., Cohen, M.A., 1998. The stabilizing effect of inventory in supply chains. Operations Research 46 (3), 572-583.

[2] Cooke, J.A., 1993. The $\$ 30$ Billion promise. Traffic Management 32, 57-59.

[3] Forrester, J., 1958. Industrial dynamics, a major breakthrough for decision makers. Harvard Business Review 36, 37-66 (July and August).

[4] Forrester, J., 1961. Industrial Dynamics. MIT Press, Cambridge, MA
[5] Holt, C.C., Modigliani, F., Muth, J., Simon, H.A., 1960. Planning Production, Inventories and Work Force. Prentice-Hall, Englewood Cliffs, New York

[6] Holmstro“m, J., 1997. Product range management: A case study of supply chain operations in the European grocery industry. Supply Chain Management 2 (3), 107-115.

[7] Lee, H.L., Padmanabhan, V., Whang, S., 1997a. The Bullwhip effect in supply chains Sloan Management Review 38 (3), 93-102.

[8] Magee, J.F., 1956. Guides to inventory control (Part II). Harvard Business Review, 106- 116.

[9] Magee, J.F., Boodman, D., 1967. Production Planning and Inventory Control, seconded. McGraw-Hill, New York.

[10] Ouyang, Y., 2007. The effect of information sharing on supply chain stability and the bullwhip effect. European Journal of Operational Research 182 (3), $1107-1121$

[11] Ouyang, Y., Daganzo, C.F., 2006a. Characterization of the bullwhip effect in linear, time-invariant supply chains: some formulae and tests. Management Science 52 (10), 1544- 1556

[12] Ouyang, Y., Daganzo, C.F., 2006b. Counteracting the bullwhip effect with decentralized negotiations and advance demand information. Physica A 363 (1), 14-23.

[13] Ouyang, Y., Daganzo, C.F., 2009. Robust stability analysis of decentralized supply chains. In: Kempf, K., et al. (Eds.), Production Planning Handbook, Springer's International Series in Operations Research and Management Science, Springer, in press.

[14] Ouyang, Y., Daganzo, C.F., 2008. Robust tests for the bullwhip effect in supply chains with stochastic dynamics. European Journal of Operational Research 185 (1), 340-353.

[15] Schmenner, R.W., 2001. Looking ahead by looking back Swift, even flow in the history of manufacturing. Production and Operations Management 10 (1), 87-95.

[16] Sterman, J., 1989. Modelling managerial behaviour: Misperceptions of feedback in a dynamic decision making experiment.Management Science 35 (3), 321339. 